\title{
Kuwaiti Instructors' Beliefs about English Language Teaching and Their Awareness of Global English
}

\author{
Ahmad F. Alnwaiem ${ }^{1}$, Abdullah M. Alazemi ${ }^{2} \&$ Abdullah A. Alenezi $^{2}$ \\ ${ }^{1}$ Department of Curriculum and Instruction, College of Basic Education, The Public Authority for Applied \\ Education and Training, Kuwait \\ ${ }^{2}$ Language Center, The Public Authority for Applied Education and Training, Kuwait \\ Correspondence: Ahmad Alnwaiem, College of Basic Education, The Public Authority for Applied Education \\ and Training, Kuwait.
}

Received: March 15, 2021

Accepted: March 29, 2021

Online Published: March 30, 2021

doi: $10.5539 /$ elt.v14n4p87

URL: https://doi.org/10.5539/elt.v14n4p87

\begin{abstract}
The beliefs of EFL teachers are an essential term perceived in a number of educational fields. Especially in teacher education and behavioural research, this term is usually related to teachers' habits and practices in classes, considering their impact on each other. The aim of this study is to add to prior studies on the subject of teachers' beliefs and to concentrate on English language teachers (ELT). The objective is to merge the theory of instructors' beliefs with Global English (GE). The research question 'what are the Kuwaiti instructors' beliefs about ELT and their awareness of Global English?' formalizes these aims. To accomplish the research: To discover teachers' beliefs about ELT and their awareness of Global English. This research concentrates on English language teachers at the university level. The collection of data has been conducted over two months. For data collection and interpretation, this study adopted a qualitative research methodology. Surveys were chosen as the instrument for data collection. The study used qualitative content analysis in relation to the data analysis method. Moreover, the findings were evaluated based on a deductive and inductive approach to qualitative data analysis. Results indicated various kinds of teachers' beliefs about ELT. Including views about the English language, ELT in relation to the standards, ELT with regard to the GE context. English-language beliefs played a central role in shaping two other views, which were considered secondary beliefs. Except for the content of teachers' beliefs, the study's findings have shown two significant categories of influences: internal and external, that affect the development and application of teachers' beliefs in classrooms.

In this study, the internal factor referred mainly to English-language teaching beliefs based on its ability to influence other cognitive constructs (i.e., different convictions, behaviours, sensitivity) and teaching practices. As far as external factors are concerned, the teachers' diverse experiences with individuals (e.g., parents and retired teachers) and administrative legislation (e.g., policy and curriculum) are the main factors.

Finally, it was possible to conclude the findings of this analysis in the same manner as previous studies, which combined teacher cognition theory with the field of GE. In other words, teacher beliefs play a crucial part in the teacher's cognitive system as a decisive role in their teaching practice. This study proposes further research to reinforce the results of contemporary research in this area.
\end{abstract}

Keywords: Kuwaiti EFL instructors, higher education, global English, English language teaching, public universities

\section{Introduction}

The spreading of English as a global language has been the subject of study for many decades. Kachru (1992/2007), an Indian linguist, offers a framework for identifying English diversity in various socio-linguistic settings worldwide in his model of the three concentric circles. This theory poses an exciting account of an understanding of English's spread and position in the present day. In Taiwan, the term "English Fever" was coined to indicate the considerable demand for society to learn English in the modern world (Chiang, 2014, p. 239). Currently, English seems to be a 'national sport' in Taiwan that people show passion and anxiety about (Yann \& Su, 2008, p. 202). Personally, this pressure motivated me to study English in different learning environments. I will begin my study by summarizing my trajectory of English and global issues. 
People must explore their personal experience and inspiration because "narratives" are essential in education qualitative research to "make sense of their experience" (Seidman, 2013, p. 8). In research, narratives and personal experiences have methodological value too. When researchers participate in "interaction" with materials in analysis, their intimate knowledge should be noted as it helps to understand the data interpretation process (Seidman, 2013, p. 26).

Consequently, starting with my personal experiences and motivation has methodological and epistemological ramifications for this study, as they help me sustain a crucial two positionality while continually focusing on research methodology, data analysis, and my engagement with participants.

English is the world's most widely spoken second language. Kuwaitis use the English language to access scientific journals, acquire information on technology, and communicate with people from English-speaking countries for education purposes. In China, learning English enables citizens to advance economically and participate effectively in the modern world (Cheng, 2011, p. 134). A 12-year-old Chinese boy said (as quoted in Nihalani, 2010), "If you can't understand English, it's like you're deaf and dumb" (p. 24). "We will not win in world competition unless South Korea masters the lingua franca of the Internet age," former South Korean President Kim Dae Jung (as quoted in Nihalani, 2010) told his people. If you don't learn English, you'll be left behind" (p. 24). In a variety of foreign contexts, Yano (2001) emphasizes the importance of using English for Japanese people to interact with the broader world (p. 127). If Japanese people want good prospects, Nihalani (2010) believes that learning English is compulsory (p. 24). According to Hsieh (as cited in Chen \& Hsieh, 2011), learning English in Taiwan is like having a "passport to the world." English is not only a subject taught in schools in Taiwan; it is also the predominant language in the modern world. As a result, more than half of Taiwanese people study English to increase career opportunities (pp. 85-86). Taiwan's president wished for English to be taught as a second language in Taiwan. The education minister said that he would arrange to use English as an official language (Honna, 2006, p. 126).

In Vietnam, English is often used as a prerequisite for having better work. To be sent as workers overseas, the Vietnamese government requires that employees be proficient in English. Furthermore, learning English provides Vietnamese people with excellent opportunities to obtain high-ranking positions in the local workforce (Hang, 2009, pp. 177-178). In Macao, English Proficiency has become a necessity and a prerequisite for obtaining suitable employment (Young, 2011, p. 127). In Mongolian schools in the 1990s, English replaced Russian as the taught foreign language (Ostler, 2010, p. 15). In Thailand, learning English starts in the first grade in private schools, the third grade in a university school, and the fifth grade in a public school. In Indonesia, English has replaced Dutch and is taught as a second language beginning in fifth grade (Bautista \& Gonzalez, 2006, pp. 137-138). In Hong Kong, English is taught alongside other subjects in kindergarten and preschool and is considered an essential part of the school curriculum (Lee, 2005, p. 38).

\section{Literature Review}

English has been the most commonly spoken as a foreign language, uniting the world into one connected world. It has evolved into a global means of interaction for people of various racial and cultural backgrounds (Ur Rahman \& Alhaisoni, 2013). English is used as a teaching medium in educational institutions in the Kingdom of Saudi Arabia (Yusuf, 2017). As a result, all public Saudi universities and institutions of higher learning require students to take an English proficiency test to be considered for admission and enrolment in their specialization of choice. Kuwait's Ministry of Higher Education has paid particular attention to advancing the process of teaching and learning English as a foreign language, given its significance in various fields of study (Yusuf \& Atassi, 2016).

Recent studies in the fields of Teaching English and applied linguistics has focused on global perceptions toward English, and there is an increasing body of research that explores the roots of difference and inconsistency in these perspectives, as well as how they affect English language teaching, policy-making, and implementation (Nunan, 2003). Following a study of the literature, two major viewpoints on disseminating English across the world emerged. The theories of anti-linguistic imperialism (Phillipson, 2012), the challenge to linguistic biodiversity (Calvet, 2006), and socio-economic inequality between and within nations, contributing to inequity, are among the most critical and ominous (Pennycook, 2017). The other viewpoint is optimistic about the role of English and has good ELT curriculum and pedagogy ideas (Jenkins, 2006; Seidlhofer, 2004). In his poignantly titled novel, English as a Global Language, David Crystal (2017) argues that English is an influential language with an extraordinary status as a global lingua franca that no other language in humankind has accomplished. One of the main reasons is that there has never been a time in human history when many states have needed to and can engage with each other as much as they do today. Fundamentally, this means that because English 
became a lingua franca in the twentieth century, against the landscape of globalization in many areas of human life, people's attitudes toward English have shifted. As several scholars have noted, an academic debate has escalated and differed over the last few years (Seawright, 2014; Block, 2010; Kumaravadivelu, 2008). According to Holliday (2015), such a shift in attitudes and practices that consider English a cultural and linguistic resource will take time and effort, with the teacher playing a pivotal role. Fang (2017), Dewey (2012), and McKay (2002), for example, concentrate on the theory of English globalization and the dissemination of English as a foreign language in consideration of whose principles should be followed. They address ELT pedagogy and evaluation issues, especially concerning the question of native vs. non-native speaker varieties. Must a native English speaker remain the standard for English-language learners, even with the likelihood that their English-language skills will be used to interact primarily with non-native English speakers?

Fang (2017) highlights that traditional ELT instructional materials and pedagogical methods are not suited to the latest practical applications of English as a foreign language. Such materials and practices, whether in the outer circles or the expanding circle, cannot meet the increasing and versatile demands of the majority of English language students. Like Fang (2017) and McKay (2002, Matsuda (2017) emphasize the need for an EIL-informed approach to the teaching of English. Although there are several definitions for the word 'language attitudes', Richards and Schmidt's (2010) definition is used for this study: Attitudes of speakers of different languages or varieties of language have to do with each other's languages or with their own languages. Positive or negative language expression can indicate feelings of linguistic difficulty or simplicity, learning facility or complexity, level of importance, beauty, social status, etc. Attitudes towards a language can also indicate what people feel towards speakers of the language.

Attitudes to language can affect the acquisition of a second language or a foreign language. Measurement of language attitudes offers knowledge that is useful in teaching and preparation (p. 314). Studies reviewed in the context of this research have shown that perceptions towards English as a foreign language can be categorized as follows:

1) Attitudes to English generally; in respect to its role in students' growth (social, cultural, academic, etc.).

2) Attitudes towards English as a lingua franca in the modern world and its effects on local languages and users.

3) Attitudes towards Standard English, dialects, and language ownership issues.

4) Attitudes towards the policies of English education in communities of expanding circle.

Prior studies showed the effect on pedagogical practice that the attitudes of students and teachers towards English have. McKay (2000) shows that Indians are shifting their attitudes towards the native speaking style of pronunciation. Her research indicates that English-speaking students tend to reject the British Received Pronunciation as unacceptable.

The results of McKay (2000) indicate that factors related to attitude and perception are relevant to native and non-native EFL users, and the social and cultural aspects of English as a foreign language can determine classroom objectives and teaching methods.

\section{Research Objective}

This research's primary objective is to obtain data on teachers' beliefs regarding ELT and awareness of Global English teaching English as a foreign language in higher education by Kuwaiti EFL instructors at various public colleges and universities in Kuwait. This can be summarised with the following objective:

\section{To investigate and discover teachers' beliefs about ELT and their awareness of Global English.}

\subsection{Research Question}

The current study seeks to answer the following research questions to achieve the aforementioned objective:

\section{What are the Kuwaiti instructors' beliefs about ELT and their awareness of Global English?}

\section{Significance of the Study}

This study aims to help EFL instructors and students at higher education level understand the impact of teachers' beliefs about ELT and their knowledge of Global English on teaching. Kuwaiti male and female EFL instructors teaching at various public higher education institutions in Kuwait produce the study. This research will benefit EFL students by equipping them with fresh insight and skills that will allow them to be prepared for and mindful of the hurdles they will encounter. Even if an EFL learner has a working understanding of the target language's grammar, they can lack the necessary training to meet the demands. It will also make recommendations to 
curriculum designers and authors of course material on incorporating elements that emphasize skill development, instructor preparation, and knowledge of current teaching strategies. In this regard, this study's results and conclusions will significantly support research on English teaching in a Kuwaiti EFL background.

\section{Research Methodology}

To address the study question, the researchers used simi-structrued interviews to gather data from the participants. This research study's research instrument is both adopted and modified. The effect of Kuwaiti instructors' views regarding ELT and their knowledge of Global English was measured using standard deviation. 26 people were included in the study. The sample was chosen at random, with no regard for gender, age, or place. Kuwaiti universities employ EFL instructors from a range of areas and districts throughout the country. Since social-class disparities expressed and replicated in schools have significant consequences on students' outcomes, the population reflects almost all of the country's current socio-economic groups, such as low, middle, and high classes. Their ages range from 35 to 50 years old, but they are not the same gender. In terms of race, first language (Arabic), English proficiency, and educational history, they are homogeneous. By evaluating the literature and previous studies in ELT, the researchers created a checklist of ELT teaching requirements for Kuwaiti public universities. To ensure that the research instruments were accurate and reliable, the researcher piloted a survey for participants who were not part of the main study group, and this was in order to ensure that the research tool was ready to be administrated to respondents. For collecting and interpreting the elicited results.

Participants for the survey are currently employed as English language instructors in various Kuwaiti universities and colleges. Demographic information includes the names of the educational organizations where the respondents serve to protect confidentiality in accordance with the study's guidelines. They all took part in the survey, and they all supported 76 ELT training courses for undergraduate students at their educational institutions. 13 males and 13 females were among the participants. Three of the six participants have Ph.D.'s in education, focusing on teaching English to non-native English speakers (TESOL). The remaining three all have Ph.D.'s in English, with others specializing in English literature and some in applied linguistics.

\section{Data Collection}

Data were gathered in this study using qualitative in-depth interviews. Responses of the participants indicating their view of English as a foreign language have been documented and transcribed. The interviews were led by a semi-structured procedure based on open-ended questions. The use of a semi-structured open-ended survey questionnaire was to provide a rich overview of the core phenomenon and cover as much of the various viewpoints and realities that reflect the collective perception of English education in Kuwait.

\section{Results and Discussions}

\section{Instructors' viewpoints on the role of EIL and the status of English in education.}

A multitude of views has been expressed based on the qualitative data collection. Some participants in the study indicated that perhaps the position of English in Kuwait is evolving, while others suggested that it is static and does not represent the unique position of English as the global language that mirrored in educational experiences in other countries regionally and internationally. The unique global position of English and its significance and value in education shared opinions among the participants. In all cases, teachers have conveyed the great importance of studying English and have been expressive of the concept of English's status and position. However, not all of them decided on a pedagogical and policy solution aimed at resolving the development of the status of English and the changing linguistic environment. When asked about the role of English in education in Kuwait, two participants were very critical of the restricted role of English while stressing its importance for interaction, education, and development. In general, these two teachers believed that crucial measures needed to resolve English's limited presence in education in Kuwait were required. Participants in the study responded by saying that the importance of English in learning is insignificant and inadequate. The importance of English should be far greater than it is currently, as English is all around us and is a necessity in every academic area of study. They proceeded to outline what they feel were the goals of learning the language and how important the role of education in achieving these objectives: In Kuwait, the primary purpose of teaching English is to provide learners with sufficient knowledge of the fundamentals of English as a foreign language, to enable learners to understand English culture, lifestyle, and literature, to equip learners with reading and writing skills, and to prepare students for postsecondary education in Kuwait or abroad.

Participants in the study also stated that: the role of English in education in a country like Kuwait is minimal. They do not think it's growing; if it is expanding, they believe the growth rate is slow because Kuwait needs a great deal of effort to develop effectively. In relation to the role of English in learning, it was also noted that: the role of English is minimal; English is taught as a foreign language, not a second language. After graduation, students 
rarely use English. We need to extend and improve our methods of teaching English in Kuwait because it is a lingua franca, and it is our responsibility to increase the aspirations of our students by introducing new teaching methods while using English as a second language as is done in many countries. As aforementioned, there were differences of opinion as to whether or not the presence of English in education in Kuwait was expanding. For example, one teacher shared a different view from the opinion expressed by another research participant. The same participant pointed out that the importance of the English language is growing, stressing that: it is also expanding in Kuwait's sense. You can see that many universities are using English as the primary language of instruction. It is also important to improve students' writing and reading skills and improve their knowledge of other languages. English is of immense significance, and a great deal of focus is paid in Kuwait because it is the world's second language. One participant who said also articulated this view of the growing importance of English and the ever-increasing desire to learn it: in Kuwait, citizens have begun to notice the necessity of English proficiency, particularly after the events of 2003. Increasing demand among citizens and residents to learn English is evident and can be observed from the growing number of private-sector English-language centres nationally. Particularly now, with the expansion of online education, a lot of content is given in English. The other participants shared these experiences. One participant reiterated some of these insights on the importance and standing of English in education in Kuwait, stating that: English plays a crucial role, and because it is the language of many academic disciplines, it offers up scope for English users here in Kuwait to enrich their experience and expertise in various facets of their academic life. It enables researchers, learners, university lecturers to stay up-to-date, collaborate, and interact with their peers in other countries.

Another participant had a similar outlook on the importance and position of the English language. He underscored its global and local significance for learners. He believed English was a dominant foreign language. His statement below reflects the following ideas: English has been and continues to be a global communicative medium that is important for interpersonal contact worldwide. Therefore, acquiring English is essential to Kuwaiti learners, as it is the primary language for study in both academic and non-academic fields. Overall, the general premise of these accounts concerning the importance and position of English as a foreign language is that English is an essential communication tool. It is an inherently necessary and useful ability and a powerful communicative force, for example, in educational, research, and technical fields.

\section{The Perceived Role of English in Expanding Knowledge In several cases}

Teachers have shared the conviction that English will be a catalyst for expanding expertise and practice in all academic disciplines. One participant figured that most terminology in academic fields is in English. Accessing literature as well as writing publications in reputable journals often needs a strong command of the English language to do this." Many of the participants' comments demonstrated the recognition on the part of the teacher that learning the English language would help learners, researchers, and practitioners broaden their skillset and knowledge. An element of the idea of English's position in spreading knowledge was the perception of English as a tool for constructing and sharing information outside the local context, while another was the view of English as a tool for constructing and enhancing learning beyond the local context. "English is all around us and is a must in every area of study." Therefore, it is a gateway into human understanding and thinking. In addition, one participant stressed that "many universities use English to provide some of their course content as well as some instructors' teaching" in Kuwait; English is becoming a medium of understanding even in the local context.

"The language of many domains," said another participant "opens up a wide scope for English speakers here in Kuwait to expand their skills and perspectives in various areas of their academic career." Since it is the language of "science and the universal tool of contact among the countries of the world," the English language "will extend our comprehension." These viewpoints reflect the assumption that English "is the main language for study in many academic and non-academic fields."

Moreover, as one participant put it, "English is an important link to access online data/literature in every field of study as it is the dominant medium of communication online." According to another, mastering the English language aids in "offering the learners with sufficient knowledge." It will help "embolden learners and prepare them for higher education. The participants were enthusiastic about the idea of English as a tool for students to broaden their understanding and experience.

Other participants' experiences demonstrated how the English language has a wealth of educational material and learning opportunities. One participant, who used the current covid-19 pandemic to discuss online education "With the growth of the online education, a lot of educational content is given in English with subtitles and explanations", articulated this idea. On multiple occasions during the surveys, the teachers mentioned English as a tool for knowledge development. The assertion that English language learning "may improve people's character and 
knowledge" reflected this viewpoint on learning English. A further facet of the English and language dissemination idea is the idea of expressing local knowledge and adding to the body of knowledge outside of the current context. "English language learners should look at their own society and knowledge from a global perspective," said the same participant. In addition, as another stated, learning English "may help learners comprehend on a global scale" and "increases the learners' abilities to share information and knowledge."

\section{Conclusion}

In our globalised society, English has evolved to become an indispensable component of every rich educational experience over the last two decades. To respond to the phenomena of English as a foreign language, ELT teaching materials and pedagogical methods must be re-examined in relation to the importance and position of English in education. The argument is not about whether English is a global language or not; it is about how attitudes toward or perceptions of the truth of English affect how we prepare curriculum, educate, read, and assess English. We are convinced that educators should be made conscious of the importance of fostering a permissive mind-set and attitudes toward English as a means of enriching the language medium rather than as a dry and despised academic topic. I hope that this review will be of assistance in this respect, and that it will bring the topic of English as a foreign language into a wider discussion in which both researchers and readers will participate.

\section{References}

Bautista, M. L. S., \& Gonzalez, A. B. (2006). Southeast Asian Englishes. In B. B. Kachru, Y. Block, D., \& Cameron, D. (Eds.), Globalization and language teaching. London: Routledge.

Block, D. (2014). Second language identities. London: Bloomsbury.

Chen, I, W., \& Hsieh, J. J. (2011). English language in Taiwan: An examination of its use in society and education in schools. In A. Feng (Ed.), English language education across Greater China (pp. 70-94). Bristol, Buffalo, and Toronto: Multilingual Matters. https://doi.org/10.21832/9781847693518-006

Chiang, C.-M. (2013). A discourse analysis of global education elements in English textbooks of junior high school: Taking $K$ edition as an example (Master's thesis, Tamkang University, New Taipei City, Taiwan). Airiti Library. https://doi.org/10.5297/ser.1201.002

Crystal, D. (2017). English as a global language. Cambridge, UK: Cambridge University 136 Press.

Dewey, M. (2007). English as a lingua franca and globalization: an interconnected perspective. International Journal of Applied Linguistics, 17(3), 332-354. https://doi.org/10.1111/j.1473-4192.2007.00177.x

Hang, P. T. T. (2009). Impacts of Vietnam's social context on learners' attitudes towards foreign languages and English language learning: Implications for teaching and learning. The Asian EFL Journal Quarterly, 11(4), 169-188.

Holliday, A. (2015). The struggle to teach English as an international language. Oxford: Oxford University Press.

Honna, N. (2006). East Asian English. In B. B. Kachru, Y. Kachru, \& C. L. Nelson (Eds.), The handbook of world Englishes (pp. 114-129). Oxford: Blackwell Publishing. https://doi.org/10.1111/b.9781405111850.2006.00011.x

Jenkins, J. (2007). English as a lingua franca: Attitude and identity. Oxford: Oxford University Press.

Kachru, \& C. L. Nelson. (Eds.). The handbook of world Englishes (pp. 130-144). Oxford: Blackwell Publishing. https://doi.org/10.1111/b.9781405111850.2006.00012.x

Kachru, B., Kachru, Y., \& Nelson, C. (2009). The handbook of world Englishes. S.1.: JOHN WILEY \& SONS.

Kumaravadivelu, B. (2008). Cultural globalization and language education. New Haven: London.

Lee, L. (2005). English language teaching in Hong Kong special administrative region (Hksar): A continuous challenge. In G. Braine (Ed.), Teaching English to the world: History, curriculum, and practice (pp. 35-45). Mahwah, NJ and London, UK: Lawrence Erlbaum Associates, Publishers.

Lin, L. C., \& Cheng, C. P. (2010). Research trends in selected MA TESOL programs in Taiwan: A preliminary content analysis of master's theses from 2003-2007. Asian EFL Journal, 12(4), 126-139.

Mahboob, A., \& Elyas, T. (2014). English in the kingdom of Saudi Arabia. World Englishes, 33(1), 128-142. https://doi.org/10.1111/weng.12073

Marefat, F., \& Pakzadian, M. (2017). Attitudes towards English as an international language (EIL) in Iran: Development and validation of a new model and questionnaire. Iranian Journal of Applied Language Studies, 9(1). 
Matsuda, A. (2017). Preparing teachers to teach English as an international language. Bristol; Blue Ridge Summit: Multilingual Matters. https://doi.org/10.21832/9781783097036

McKay, S. L. (2004). Teaching English as an international language: The role of culture in Asian contexts. The Journal of Asia Tefl, 1(1), 1-22.

Nihalani, P. (2010). Globalization and international intelligibility. In M. Saxena \& T. Comoniyi (Eds.), Contending with globalization in world Englishes (pp. 23-44). Bristol, Buffalo, and Toronto: Multilingual Matters. https://doi.org/10.21832/9781847692764-005

Ostler, N. (2010). The last lingua franca: English until the return of Babel. New York: walker \& Company.

Pennycook, A. (2017). The cultural politics of English as an international language. Milton Park, Abingdon, Oxon: Routledge. https://doi.org/10.4324/9781315225593

Phillipson, R. (2012). Linguistic imperialism. Oxford: Oxford University Press. https://doi.org/10.1002/9781405198431.wbeal0718

Pishvaei, V., \& Kasaian, S. A. (2013). Design, Construction, and Validation of a Critical Pedagogy Attitude Questionnaire in Iran. European Online Journal of Natural and Social Sciences, 2(2).

Richards, J. C., \& Schmidt, R. W. (2010). Longman dictionary of language teaching and applied linguistics. Routledge.

Seawright, L. (2014). Going global: Transnational perspectives on globalization, language, and education. Newcastle upon Tyne: Cambridge Scholars Press

Seidman, I. E. (2013). Interviewing as qualitative research (4th ed.). New York, NY: Teachers College Press.

Ur Rahman, M. M., \& Alhaisoni, E. (2013). Teaching English in Saudi Arabia: Prospects and challenges. Academic Research International, 4(1), 112.

Yann, C.-C., \& Su, R.-S. (2008). Discussion of myths and controversies in English education in Taiwan. Journal of Humanities, College of Liberal Arts, National Chung Hsing University, 41, 201-214.

Yano, Y. (2001). World Englishes in 2000 and beyond. World Englishes, 20(2), 119-132. https://doi.org/10.1111/1467-971X.00204

Young, M. Y. C. (2011). English use and education in Macao. In A. Feng (Ed.), English language education across Greater China (pp. 114-130). Bristol, Buffalo, and Toronto: Multilingual Matters. https://doi.org/10.21832/9781847693518-008

Yusuf, N., \& Atassi, H. (2016). Beyond Oil - The Transformation to a Market-Based Approach: Envision Saudi Arabia 2030. Journal of Economics and Sustainable Development, 7(14), 20-24.

Yusuf, N. (2017). Changes Required in Saudi Universities Curriculum to Meet the Demands of 2030 Vision. International Journal of Economics and Finance, 9(9), 111-116. https://doi.org/10.5539/ijef.v9n9p111

\section{Copyrights}

Copyright for this article is retained by the author(s), with first publication rights granted to the journal.

This is an open-access article distributed under the terms and conditions of the Creative Commons Attribution license (http://creativecommons.org/licenses/by/4.0/). 